\title{
Airway dysfunction in elite swimmers: prevalence, impact, and challenges
}

\author{
This article was published in the following Dove Press journal: \\ Open Access Journal of Sports Medicine \\ 12 May 2016 \\ Number of times this article has been viewed
}

\section{Mitch Lomax \\ Department of Sport and Exercise Science, University of Portsmouth, Portsmouth, UK}

Correspondence: Mitch Lomax Department of Sport and Exercise Science, University of Portsmouth, Spinnaker Building, Cambridge Road, Portsmouth, POI 2ER, UK

Tel +442392845297

Email mitch.lomax@port.ac.uk
Abstract: The prevalence of airway dysfunction in elite swimmers is among the highest in elite athletes. The traditional view that swimmers naturally gravitate toward swimming because of preexisting respiratory disorders has been challenged. There is now sufficient evidence that the higher prevalence of bronchial tone disorders in elite swimmers is not the result of a natural selection bias. Rather, the combined effects of repeated chlorine by-product exposure and chronic endurance training can lead to airway dysfunction and atopy. This review will detail the underpinning causes of airway dysfunction observed in elite swimmers. It will also show that airway dysfunction does not prevent success in elite level swimming. Neither does it inhibit lung growth and might be partially reversible when elite swimmers retire from competition.

Keywords : exercise, aquatic athletes, bronchoconstriction

\section{Introduction}

Athletes born free from airway disease, such as asthma, are not exempt from developing respiratory disorders over the course of their competitive careers. The International Olympic Committee recognizes that endurance exercise itself is capable of increasing the risk of airway dysfunction. ${ }^{1}$ While this is true of elite endurance athletes in general, ${ }^{2}$ it is also true that the sport of swimming displays a comparatively high rate of airway dysfunction. ${ }^{3,4}$

The traditional explanation for this higher prevalence rate is one of selection bias. The suggestion that swimming is a more suitable activity compared to both cycling and running in asthmatics ${ }^{5}$ is not surprising. For example, the hydrostatic compression effect of water can reduce the effort required to generate expiratory flow, while the natural hypoventilation and increase in central blood volume reduce inspiratory tract heat $\operatorname{loss}^{6}$; however, the hydrostatic pressure also increases the resistance during exhalation when exhaling into the air. On top of this, the aquatic environment is associated with a lower pollen count. ${ }^{6}$ Coupled with the inhalation of warm humid air, this reduces the risk of asthma exacerbation ${ }^{5,6}$ It is therefore unsurprising that swimming does not adversely affect the control of asthma in children or adolescents. ${ }^{7,8}$

Despite these aquatic environment advantages, a recent Cochrane review concluded that there is insufficient evidence to suggest that aquatic-based exercise is superior to comparative nonaquatic exercise in asthmatics. ${ }^{9}$ Moreover, it has been shown that adolescent elite swimmers do not necessarily begin their competitive careers with airway dysfunction. ${ }^{10}$ There is now sufficient evidence that repeated exposure to chlorinated swimming pool water predisposes swimmers to develop airway dysfunction. ${ }^{11-17}$ This

submit your manuscript ! wank dore 
Table I $\dot{V} O_{2}$ peak, $\dot{V}_{E}$, breathing frequency, and tidal volume measured during all-out front crawl, back stroke, or breast stroke swimming in trained swimmers

\begin{tabular}{|c|c|c|}
\hline Parameter & Range & References \\
\hline $\begin{array}{l}\text { Breathing frequency } \\
\text { (breaths } / \mathrm{min} \text { ) }\end{array}$ & $39-57$ & $21^{b}, 22^{b}, 37^{a}, 74^{a}$ \\
\hline Tidal volume (L) & $1.43-3.53$ & $21^{\mathrm{b}}, 22^{\mathrm{b}}, 23^{\mathrm{c}}, 37^{\mathrm{a}}, 74^{\mathrm{a}}$ \\
\hline$\dot{V}_{E}(L / m i n)$ & $68-152$ & $20^{\mathrm{a}}, 21^{\mathrm{b}}, 22^{\mathrm{b}}, 23^{\mathrm{c}}, 37^{\mathrm{a}}, 74^{\mathrm{a}}$ \\
\hline$\dot{\mathrm{V}} \mathrm{O}_{2}$ peak $(\mathrm{L} / \mathrm{min})$ & $2.49-5.08$ & $\begin{array}{l}19^{\mathrm{a}}, 20^{\mathrm{a}}, 21^{\mathrm{b}}, 22^{\mathrm{b}}, 23^{\mathrm{c}}, 37^{\mathrm{a}}, \\
74^{\mathrm{a}}, 75^{\mathrm{c}}, 76^{\mathrm{a}}, 77^{\mathrm{a}}, 78^{\mathrm{a}}, 79^{\mathrm{a}}\end{array}$ \\
\hline$\dot{V} \mathrm{O}_{2}$ peak $(\mathrm{mL} / \mathrm{kg} / \mathrm{min})$ & $49.8-69.9$ & $19^{\mathrm{a}}, 23^{\mathrm{c}}, 24^{\mathrm{a}}, 37^{\mathrm{a}}, 76^{\mathrm{a}}, 78^{\mathrm{a}}, 79^{\mathrm{a}}$ \\
\hline
\end{tabular}

Notes: Measured during: aprogressive intensity swimming; ball-out swimming until exhaustion; call-out $400 \mathrm{~m}$ or 400 yard swim.

Abbreviations: $\dot{\mathrm{VO}}_{2}$, oxygen uptake; $\dot{\mathrm{V}}_{\mathrm{E}}$, minute ventilation.

implies that the exercise environment leads to bronchial tone disorders ${ }^{10}$ and contradicts the traditional view that asthmatic individuals naturally gravitate toward the sport of swimming. Consequently, the high prevalence of airway dysfunction in elite swimmers can no longer be attributed to a selection bias. ${ }^{10,16}$

The aim of this review is to examine 1) the reasons why elite swimmers are particularly susceptible to the development of airway dysfunction and 2) the impact and challenges of diagnosing airway dysfunction. It is appropriate to begin by reviewing how the uniqueness of an aquatic environment challenges the lung.

\section{The trouble with water}

The most obvious difference between swimming and exercise of a terrestrial nature is that the former takes place with the body horizontal while immersed in water. As the density of water is $\sim 800$ times greater than that of air, ${ }^{18}$ these factors collectively have a marked effect on the cardio-pulmonary responses to exercise. For example, maximum heart rate, ${ }^{19-24}$ maximum cardiac output, and maximum oxygen uptake $\left(\dot{V} \mathrm{O}_{2}\right)^{19-22,24}$ are lower during swimming compared with walking, running, or cycling, although this also reflects the smaller muscle mass recruited in swimming.

The hydrostatic load created by the water limits the expansion of the chest wall and lungs ${ }^{25}$ pushing the chest wall inwards ${ }^{26}$ and reducing residual gas volume. ${ }^{27}$ It also narrows airways larger than $2 \mathrm{~mm}$ in diameter, which is where $90 \%$ of flow resistance occurs. ${ }^{28}$ Because of the hydrostatic compression and the horizontal body position, ${ }^{29}$ blood flow is shifted from the extremities into the chest. ${ }^{26,30}$ The increased hydrostatic load (which counteracts inspiratory muscle force) and pulmonary engorgement (which reduces lung compliance by filling spaces in the thoracic cavity with blood rather than air) reduces total lung capacity, ${ }^{31}$ vital capacity, and the expiratory reserve volume..$^{26,30,32,33}$ Nonetheless, trained swimmers have a higher forced vital capacity, forced expired volume in the first second of exhalation, total lung capacity, vital capacity, inspiratory capacity, and pulmonary diffusion capacity and chest surface area compared with runners. ${ }^{34-36}$

Additionally, tidal volume tends to be higher and breathing frequency lower and with a more rapid inhalation phase ${ }^{34}$ in swimming (Table 1) compared with spontaneously breathing submaximal ${ }^{19,22}$ and maximal ${ }^{22,23}$ walking, running, and cycling exercise. This is because breathing must be coordinated with stroke mechanics, meaning that it cannot occur ad libitum. ${ }^{22,34,37}$ The one exception to this is back stroke. As the face is not immersed in water during back stroke, breathing is not physically impeded. However, this also means that the mouth and nose spend more time exposed to the water-air interface compared with front crawl, breast stroke, and butterfly. Importantly, chlorine by-products reside here. ${ }^{38}$

Chlorination is the most widely used method to disinfect pool water. ${ }^{39}$ It involves adding small amounts of chlorine to water in various forms, all of which release weak hypochlorous acid. ${ }^{38}$ The most common disinfectant used in public pools in the UK is hypochlorite. ${ }^{40}$ The World Health Organization ${ }^{39}$ suggests that the concentration of free (available to disinfect) chlorine should not exceed $3 \mathrm{mg} / \mathrm{L}$ in public pools. In the UK where hypochlorite is typically used, a minimum of $0.5 \mathrm{mg} / \mathrm{L}$ and maximum of $1 \mathrm{mg} / \mathrm{L}$ is recommended. ${ }^{40}$

When reacting with organic or inorganic matter, a number of chlorinated oxidants or derivatives (by-products) are produced which can be inhaled, ingested, or absorbed via the skin. ${ }^{38,39}$ The concentration of chlorine by-products at or above the water surface is not simply a matter of the chlorine dosage. By-product level will vary with factors, such as chlorine dosing, air temperature, adequacy of pool area ventilation, and swimmer/bather load.$^{38}$ Swimmers are exposed to such by-products (eg, trichloramine, hypochlorous acid, and mono- and dichloramine) when inhaling air and aerosols floating just above the water surface. This is particularly problematic during exercise because of the shift from nasal breathing at rest to oral nasal breathing during exercise. Consequently, the air inhaled undergoes less filtration by the nasal cavity and chlorinated by-products are able to travel further into the lungs. ${ }^{38}$

A shift from nasal to mouth breathing occurs at ventilations as low as $22 \mathrm{~L} / \mathrm{min},{ }^{41}$ which is substantially lower than the minute ventilation $\left(\dot{V}_{\mathrm{E}}\right)$ observed during maximal swimming (see Table 1). Such a ventilation is exceeded 
when swimming below 50\% of maximal (max) or peak $\dot{V} \mathrm{O}_{2}$. Considering that an economical technique may require a pace equivalent to at least $40 \%$ of $\dot{V} \mathrm{O}_{2 \max },{ }^{22}$ swimmers do not need to be exercising particularly hard before their airway epithelium is subjected to increased oxidant stress arising from less air filtration. This raises an interesting and unexamined question. Are back stroke swimmers more at risk from airway dysfunction? First, because the mouth and nose spend longer at the water-air interface per stroke cycle and second, because $\dot{V}_{\mathrm{E}}$ tends to be higher (because breathing frequency is greater) compared with the other strokes. ${ }^{20,37}$

\section{Airway injury and dysfunction The problem with endurance exercise}

The greater prevalence of airway dysfunction in nonaquatic elite endurance athletes compared with nonaquatic elite nonendurance athletes ${ }^{2-4}$ suggests that it is not just chlorine by-products that are responsible for increasing the susceptibility of elite swimmers to airway dysfunction. For example, Bonsignore et $\mathrm{al}^{42}$ found that high weekly swimming volumes $(32 \pm 15 \mathrm{~km})$ completed in an outdoor heated (typically $27^{\circ} \mathrm{C}$ ) pool were associated with airway neutrophilia, indicating increased airway inflammation. In the absence of any detectable chlorine irritants, the observed neutrophilia likely reflected the impact of chronic endurance exercise on airway health. In support of this, Martin et $a{ }^{43}$ were unable to find any difference in the level of eosinophilic inflammation between 118 aquatic-based (swimmers, water polo players, and triathletes) and nonaquatic-based (rowers, cyclists, runners, and football players) elite athletes. They found more epithelial cells in sputum and greater eosinophilic airway inflammation in athletes demonstrating a positive eucapnic voluntary hyperpnea $(\mathrm{EVH})$ test compared with those who did not. Whether or not the athlete was pool-based proved irrelevant.

Sustaining high flow rates and hence high levels of ventilation during exercise cause dehydration and cooling of the airways. ${ }^{44}$ For example, it has been shown that when $\dot{V}_{\mathrm{E}}$ increases from 7.5 to $60 \mathrm{~L} / \mathrm{min}$, total water loss from the airways per minute increases from 0.164 to $1.205 \mathrm{~mL}$, and heat loss increases from 0.0160 to $0.0567 \mathrm{kcal} .{ }^{45}$ Airway dehydration and cooling will lead to the release of inflammatory mediators ${ }^{44}$ and the accompanying hyperpnea changes the viscosity, tonicity, and volume of airway surface lining. ${ }^{46}$ Hyperpnea will therefore expose the airway epithelium to increased sheer stress and transmural pressure gradients, ${ }^{46-48}$ which in adolescents may not yet be fully matured. ${ }^{16}$ This in turn can lead to sloughing or total detachment of the dehy- drated epithelial airway cells. ${ }^{46-48}$ As the airway epithelium provides a physical barrier between inhaled air and internal body structures protecting the sensory nerves and smooth muscle cells from inhaled irritants, ${ }^{44,49}$ these cells are now at risk of penetration by pathogens. ${ }^{46}$ Additionally, disruption to the airway epithelium will lead to an increase in vascular leakage of inflammatory cells, for example, eosinophils and neutrophils, into the airways. ${ }^{50}$

The airway epithelium does repair itself. ${ }^{47,48}$ In the absence of heavy training loads, it is estimated that the upper respiratory epithelium is replenished every 30-50 days. ${ }^{49}$ However, the repeated injury-repair process induced by chronic endurance training will over time cause structural and functional changes termed airway remodeling. ${ }^{47,48}$ This in turn can lead to airway hyperresponsiveness (AHR). ${ }^{44,51,52}$ Table 2 presents an overview of airway disorders experienced by endurance athletes.

There are a number of airway changes contributing to the negative remodeling. They include epithelial metaplasia, proliferation of airway smooth muscle cells, thickened reticular basement membrane, goblet cell hyperplasia, and the deposition of plasma-derived adhesive proteins. ${ }^{15,52,53}$ Moreover, if the airways experience sufficient exposure to allergens (including chlorine by-products), allergic diseases may develop as the airways undergo remodeling. ${ }^{16}$

Importantly, environmental stressors will add to the hyperpnea-induced epithelial stress. For example, cold environments require the inspired air to be subjected to extra conditioning leading to an increase in airway dehydration. Postexercise, rewarming of the airway adds a thermal stress ${ }^{47}$ resulting in mucosal edema and bronchoconstriction. ${ }^{48}$ This may be more relevant to swimmers who train or compete in cold temperatures and, in the case of sea swimmers, are exposed to a hypertonic environment. ${ }^{42}$ Of greater relevance to this review, however, is the impact of chlorine and its by-products.

\section{Biomarkers of airway dysfunction in swimmers}

It has been found that induced sputum of elite swimmers contains increased proportions of eosinophils and neutrophils (markers of airway inflammation) and increased concentrations of soluble cell markers compared with the sputum of healthy controls. ${ }^{54}$ In addition, in well-trained swimmers (mean age of 20-21 years), epithelial desquamation, ${ }^{44}$ subepithelial fibrosis and mucin secretion, and goblet cell hyperplasia ${ }^{15}$ have been observed following an average of 10-11 years of training. Additionally, sputum bronchoprotective 
Table 2 Overview of respiratory disorders observed in endurance-based athletes

\begin{tabular}{|c|c|}
\hline Disorder & Explanation \\
\hline \multicolumn{2}{|c|}{ Bronchial tone disorders } \\
\hline Asthma & Reversible narrowing of the airways. Manifested by inflammation and widespread narrowing. \\
\hline AHR & $\begin{array}{l}\text { Allergen exposure enhances the response to exercise in asthmatics and increases the responsiveness to } \\
\text { pharmacological agents. The airways over-respond to various stimuli causing reversible airway obstruction. }\end{array}$ \\
\hline $\mathrm{BHR}$ & $\begin{array}{l}\text { Positive response to direct (eg, methacholine or histamine) and indirect (eg, exercise, EVH, or hypertonic aerosols) } \\
\text { stimuli. }\end{array}$ \\
\hline EIA & Occurs in individuals who have underlying asthma and exercise is an exacerbation trigger. \\
\hline EIB & Transient narrowing of the airways (bronchospasm) that follows vigorous exercise in individuals with no history of asthma. \\
\hline \multicolumn{2}{|c|}{ Other disorders } \\
\hline EFL & $\begin{array}{l}\text { Occurs in nonasthmatics when the tidal flow-to-volume envelope loop encroaches on the maximal loop. A } \dot{V}_{E} \text { in excess } \\
\text { of } 120-130 \mathrm{~L} / \mathrm{min} \text { is required. More prevalent in females. }\end{array}$ \\
\hline Rhinitis & $\begin{array}{l}\text { Prevalence of rhinitis in competitive swimmers is high and thought to reflect irritation of nasal mucosa by chlorinated } \\
\text { water. Symptoms include nasal obstruction, rhinorrhea, nasal burning, sneezing, and nasal itching. }\end{array}$ \\
\hline \multicolumn{2}{|c|}{ Swimming-induced pulmonary Occurs in response to a single heavy swimming session. More prevalent than nonaquatic pulmonary edema. } \\
\hline edema & Reflects pulmonary capillary stress failure brought about by immersion. \\
\hline VCD & $\begin{array}{l}\text { Associated with inspiratory wheeze. Occurs during maximal exercise. Symptoms disappear once hyperpnea or } \\
\text { hyperventilation stops. Often misdiagnosed as asthma or EIB. More prevalent in females. }\end{array}$ \\
\hline
\end{tabular}

Note: Adapted from references. $2,48,51,52,65,80-86$

Abbreviations: AHR, airway hyperresponsiveness; BHR, bronchial hyperresponsiveness; ElA, exercise-induced asthma; ElB, exercise-induced bronchoconstriction; EFL, expiratory flow limitation; EVH, eucapnic voluntary hyperpnea; $\dot{V}_{\mathrm{E}}$, minute ventilation; VCD, vocal cord dysfunction.

prostaglandin $\mathrm{E}_{2}$, which inhibits mast cell activation and induces relaxation of airway smooth muscle, ${ }^{49}$ is higher in elite pool-based aquatic athletes than nonaquatic athletes following an EVH test. ${ }^{43}$ The increased concentration of sputum prostaglandin $\mathrm{E}_{2}$ was thought to reflect the added stress placed on the airways by exposure to chlorine by-products. ${ }^{43}$

Attendance at chlorinated pools during childhood has been associated with a decrease in Club cell protein $16(\mathrm{CC} 16)^{16,55}$ and the $\mathrm{CC} 16 /$ surfactant-associated protein $\mathrm{D}$ ratio. ${ }^{16} \mathrm{CC} 16$ is an anti-inflammatory protein secreted exclusively by the Clara cells in the bronchioles. ${ }^{16,49,56}$ Surfactant-associated protein $\mathrm{D}$ is a marker of epithelial permeability ${ }^{16,56}$ and it has been shown that $11.9 \%$ of the variance observed in serum surfactant-associated protein $\mathrm{D}$ in swimmers can be explained by pool attendance. ${ }^{56}$

An increase in $\mathrm{CC} 16$ to a bronchial challenge is indicative of respiratory epithelial stress. Elevated urinary CC16 levels have been observed in adolescent and young adult (mean age of 16 years, range of 12-23 years) swimmers following an exercise challenge..$^{57}$ Romberg et $\mathrm{al}^{57}$ found that out of 101 competitive swimmers with a weekly training duration of 10-30 hours, urinary CC16 was greater following a 6-8 minute swim challenge in $90 \%$ of those sampled. Additionally, baseline CC16 was weakly correlated with the fraction of exhaled nitric oxide (FeNO) $(r=0.26, P<0.010)$. As FeNO is a surrogate biomarker of eosinophilic inflammation, this suggests a role of CC16 in airway inflammation. ${ }^{57}$

In contrast, a reduction in baseline $\mathrm{CC} 16$ likely indicates epithelial dysfunction. ${ }^{55,57} \mathrm{~A}$ fall in the production of $\mathrm{CC} 16$ could also mask an increase in the intravascular leakage of
CC16 into the airways. ${ }^{55}$ Such a leakage has been reported in elite asthmatic and elite nonasthmatic swimmers undertaking high training volumes $(12 \pm 15$ and $15 \pm 8$ hours per week, respectively) with $6 \pm 5.5$ years of competitive experience. ${ }^{50}$ Interestingly, Moreira et $\mathrm{al}^{50}$ found that the proportion of individuals demonstrating increased vascular permeability was similar between asthmatic and nonasthmatic elite swimmers and asthmatic control subjects. They also observed a high number of epithelial cells in the sputum of nonasthmatic swimmers. This may suggest developing of airway dysfunction in the nonasthmatic swimmers.

Belda et $\mathrm{al}^{14}$ observed a correlation between the duration of training and sputum neutrophil counts $(r=0.36, P=0.04)$ in elite aquatic-based, but not nonaquatic-based $(r=-0.16$, $P=0.45$ ), athletes. They suggested that the increased airway inflammatory response is likely caused by exposure to chlorine by-products. This supports the idea that cumulative life time exposure to chlorine by-products is important for the development of airway dysfunction. ${ }^{10,54,58,59}$ For example, Helenius et al ${ }^{54}$ reported that out of 29 elite Finnish swimmers, 28 were nonasthmatic at the start of their competitive careers. Over the course of their competitive careers, which lasted on average 9 years, $17 \%$ were diagnosed with asthma. Similarly, in a group of 34 Italian swimmers (age range 7-20 years) who had been competing for at least 4 years and obtained a cumulative lifetime pool attendance of over 400 hours, $68 \%$ reported at least one asthma-like symptom, $74 \%$ exhibited allergic sensitization, and 53\% demonstrated a positive response to a methacholine challenge. The proportion of swimmers with allergic sensitization and AHR was 
also greater than that expected for the general population. Importantly, none of the swimmers had selected swimming because of preexisting respiratory problems. ${ }^{59}$

Evidence available suggests that it may take at least 4 years of competitive swim training before airway dysfunction develops in swimmers, and this is typically preceded by several years of noncompetitive swimming. ${ }^{10,58,59}$ For example, Pedersen et $\mathrm{al}^{10,58}$ found that adolescent swimmers (aged 12-16 years) with 2 to 3 years of competitive experience showed no evidence of raised baseline airway inflammation even when the total swimming training exceeded 9 years. ${ }^{58}$

Similarly, Carraro et $\mathrm{a}^{60}$ found that intermittent exposure to chlorine by-products failed to negatively impact airway inflammation in response to recreational swimming. FeNO concentrations were similar among 241 children (aged 7 to 10 years) regardless of whether or not they undertook 1-2 hours of weekly swimming for 6 months. In a survey of 5,738 British school children, Font-Ribera et $\mathrm{al}^{7}$ found that swimming infrequently, once per month, once per week, or more than once a week up to the age of 7 years was not associated with the development of asthma or atopy (susceptibility to allergic reactions). On the contrary, they found that lung function was improved and the prevalence of asthma symptoms in those with respiratory conditions was improved with swimming. However, none of the swimmers in the studies by Font-Ribera et $\mathrm{al}^{7}$ and Carraro et $\mathrm{al}^{60}$ were reported to be well trained or competitive swimmers. In contrast, competitive swimmers aged 8 to 23 years are reported to spend between 10 and 30 hours in the pool weekly ${ }^{10,57-59}$ and therefore subject their airway epithelium to a much greater cumulative stress.

\section{Prevalence of airway dysfunction in elite swimmers}

The proportion of elite and highly trained swimmers suffering from some form of bronchial tone respiratory disorder is high, with reports indicating it may approach ${ }^{54,61}$ or exceed en $^{44,59,62}$ $50 \%$. A greater prevalence of asthma, AHR, and bronchial hyperresponsiveness has been reported in swimmers compared with healthy individuals, ${ }^{54,63}$ cold-weather athletes, ${ }^{3,44}$ and nonaquatic-based athletes. ${ }^{3,4,14,43}$ Furthermore, the relative risk of asthma in atopic swimmers has been shown to be greater (97-fold) than that of atopic long distance runners (42-fold) and speed and power athletes (25-fold). ${ }^{64}$

During the Olympic Games of 2004 (Athens) and 2008 (Beijing), the number of aquatic athletes with asthma was greater than nonaquatic athletes. ${ }^{4}$ When looking at the mean percentage of athletes approved to use $\beta_{2}$-agonists during the 2004 and 2008 Olympic Games, only cycling and modern pentathlon had a similar prevalence $(17.2 \%$ and $17.1 \%$, respectively) to swimming (16.8\%) with triathlon exhibiting the largest prevalence $(24.9 \%){ }^{3}$ Focusing on aquatic disciplines specifically, Mountjoy et $\mathrm{al}^{4}$ extended their assessment to include data from the World Championships and Olympic Games from 2004 until 2009. They found that divers typically had the lowest prevalence of asthma compared with swimmers, water polo players, and synchronization swimmers. In contrast, swimmers typically had the greatest prevalence, $\sim 12 \%$ to $25 \%$. Mountjoy et $\mathrm{al}^{4}$ also observed that the prevalence of asthma/AHR was greater in elite aquatic athletes in Europe, North America, and Oceania than Africa, Asia, and South America. Although the authors were unable to ascertain why, they suggested that racial or genetic differences and/or geographical differences in diagnostic evaluations of bronchial tone disorders, chlorination usage and regulation, and participation rates could be possible explanations.

\section{Impact of airway dysfunction on swimmers}

Exposure to chlorine by-products does not negatively impact lung growth. For example, baseline forced expired volume in the first second of exhalation is around 10\%-19\% higher in elite swimmers than predicted, while baseline forced vital capacity is $\sim 15 \%-34 \%$ greater. $^{10,15,43,50,57,58,61,65}$ There is also no evidence that airway dysfunction is a barrier to success in swimming. For example, in the 2004 Athens Olympic Games, 56 athletes met the International Olympic Committee Medical Commission's criteria for asthma, and went on to win a total of 17 medals (seven gold, seven silver, and three bronze).${ }^{66}$ Of the $19 \%$ of swimmers who met the International Olympic Committee-Medical Commission's criteria for using $\beta_{2}$-agonists in the 2008 Beijing Olympic Games, 33\% went on to win medals. ${ }^{3,67}$ This is similar to the percentage of cyclists approved to use $\beta_{2}$-agonists who went on to win medals at the same Olympic Games (29\%) and is greater than the percentage of medals won by all asthmatic athletes (5\%-16\%) during the Salt Lake City, Athens, Torino, and Vancouver Olympic Games of 2002 to $2010 .^{3}$

Before an elite swimmer is permitted to use a medical treatment for AHR, they must provide evidence of a positive bronchial provocation test. ${ }^{1}$ Any medication (eg, inhaled corticosteroids, inhaled $\beta_{2}$-agonists) must comply with the World Anti-Doping Agency regulations and swimmers can only use medications in accordance with Therapeutic Use Exemption. ${ }^{1,68}$

Bronchial provocation tests can be categorized as direct or indirect tests. Direct tests act on the smooth muscle cell 
Table 3 Positive test criteria for some common bronchial provocation tests: WADA guidelines

\begin{tabular}{ll}
\hline Test & Positive criteria \\
\hline EVH & $\geq 10 \%$ fall of $\mathrm{FEV}$ \\
Exercise challenge & $\geq 10 \%$ fall of $\mathrm{FEV}_{1}$ \\
Histamine challenge & $\geq 20 \%$ fall of $\mathrm{FEV}_{1}$ at a histamine concentration of $8 \mathrm{mg} / \mathrm{mL}$ or less during a graded test of 2 minutes \\
Mannitol inhalation & $\geq 15 \%$ fall in $\mathrm{FEV}_{1}$ after challenge \\
Methacholine challenge & $\geq 20 \%$ fall in $\mathrm{FEV}_{1}$. If steroid naïe $\mathrm{PC}_{20}$ should be $<4 \mathrm{mg} / \mathrm{mL}$. If taking inhaled glucocorticoids for more than I month, \\
& $\mathrm{PD}_{20}$ should be $\leq 1,600 \mu$ or $\mathrm{PC}_{20} \leq 16.0 \mathrm{mg} / \mathrm{mL}$ \\
\hline
\end{tabular}

Note: WADA guidelines. ${ }^{68}$

Abbreviations: WADA, World Anti-Doping Agency; $\mathrm{EVH}$, eucapnic voluntary hyperpnea; $\mathrm{FEV}_{1}$, forced expired volume in the first second of exhalation; $\mathrm{PC}{ }_{20}$, concentration of the agonist in the inhaled aerosol leading to a fall in $\mathrm{FEV}$, of $20 \%$; $\mathrm{PD}_{20}$, administered dose of an inhaled aerosol which causes $\mathrm{FEV}$, to fall by $20 \%$.

receptors, whereas indirect tests act through intermediate pathways and commonly via the release of mediators from inflammatory cells. ${ }^{52}$ Those used in studies of elite swimmers include methacholine challenge, ${ }^{10,44,50,61,65} \mathrm{EVH},{ }^{15,43,61,65}$ histamine, ${ }^{44,54,64,69}$ exercise challenge, ${ }^{57,61,70}$ and mannitol. ${ }^{57}$ Table 3 contains an overview of the current World AntiDoping Agency (2015) criteria for a positive bronchial provocation test.

Methacholine challenge and EVH have proved to be the most popular bronchial provocation tests used in elite swimmers. Pedersen et $\mathrm{al}^{61}$ found that EVH was more sensitive than a methacholine challenge, a laboratory-based treadmill exercise provocation test (incremental test to exhaustion), or a swimming-based exercise challenge (minimum of $200 \mathrm{~m}$ at the fastest possible speed). Of the 21 elite female swimmers they tested, 16 had at least one positive test to exercise hyperpnea or EVH. Ten (63\%) could be identified with EVH, eight $(50 \%)$ with a swimming challenge, and eight (50\%) with a laboratory-based test. Only six (38\%) could be identified with a methacholine challenge indicating that this test is the one that has the least sensitive bronchial provocation in elite swimmers. It is therefore not surprising that EVH has been proposed as the preferred test to identify exercise-induced bronchoconstriction (EIB) in these athletes. ${ }^{10,61}$

As a disconnect has been observed between symptoms suggestive of EIB and positive EIB test results, it is prudent to screen all elite swimmers for EIB. ${ }^{43,61,70}$ For example, Clearie et $\mathrm{al}^{70}$ found that less than half of the 36 elite adolescent Scottish swimmers who exhibited positive EIB results reported symptoms suggestive of EIB. However, if a positive EVH test is not observed, it should be followed up with a strenuous laboratory-based test. ${ }^{61}$ But, the timing of any such test must be given serious consideration. Bougault et $\mathrm{al}^{65}$ found that AHR and EIB can be transient during intense training. Specifically, 12 out of 19 well-trained swimmers exhibited AHR in response to either EVH or a methacholine challenge when tested during a period of intense training. When tested again following at least 15 days of light or no training, airway responsiveness to a methacholine challenge or EVH had normalized in $67 \%$ (eight) of the swimmers.

It is also relevant to note that symptoms indicative of mild asthma can be partially reversed when elite swimmers retire from competition. Over a 5-year period, Helenius et al ${ }^{69}$ monitored 42 elite Finnish swimmers, which accounted for $88 \%$ of the Finnish National swimming teams. In all, $62 \%$ retired from competition during this period while $38 \%$ continued their competitive careers. In those who continued to compete, the differential cell counts of eosinophils and lymphocytes significantly increased and the occurrence of asthma increased by $80 \%$ (from five swimmers to nine). Conversely, in swimmers who retired from competition, the eosinophil and lymphocyte differential cell counts fell and asthma decreased by $15 \%$ (from seven swimmers to six). However, the proportion of the reversal that could be attributed to reduced chlorine exposure versus reduced exercise volume was not determined.

Chlorine alternative pool water disinfection methods should also be considered in an attempt to reduce the prevalence of airway dysfunction in elite swimmers. Alternatives such as ozone, ultraviolet radiation, and copper/silver ${ }^{39,40,71-73}$ are available. However, disinfection by ozone (which itself is a major respiratory irritant) and ultraviolet radiation only purify the water as it passes through the plant room. The water that remains in the pool therefore contains no residual disinfectant. Consequently, ozone or ultraviolet radiation disinfection methods need to be used in conjunction with chlorine or bromine-based disinfectants. ${ }^{39}$

Nonetheless, the small number of studies examining chlorine alternative disinfection methods reveal promising results. For example, Carbonnelle et $\mathrm{al}^{72}$ found that a single swimming session of $1,300 \mathrm{~m}$ (45 minutes in duration) was associated with a $34 \%$ increase in FeNO when completed in a pool disinfected by the copper/silver method (ambient nitrogen trichloride concentration of $\left.<20 \mu \mathrm{g} / \mathrm{m}^{3}\right)$. Conversely, 
the expected exercise-induced increase in FeNO was inhibited when undertaken in a chlorine disinfected pool (ambient nitrogen trichloride concentration of $\left.160-280 \mu \mathrm{g} / \mathrm{m}^{3}\right)$. In a similar study, Carbonnelle et $\mathrm{al}^{71}$ observed an increase in the serum concentrations of surfactant-associated protein A and surfactant-associated protein B following 1,500 m swimming (45 minutes in duration) in a chlorinated pool (mean ambient nitrogen trichloride concentration of $355 \mu \mathrm{g}$ / $\mathrm{m}^{3}$ ) but observed no such changes in response to swimming in a copper/silver disinfected pool (nitrogen trichloride levels were too low for detection). These findings indicate that a single swimming session in a pool disinfected by the copper/ silver method does not increase lung hyperpermeability. ${ }^{71}$

Furthermore, Fernández-Luna et $\mathrm{al}^{73}$ found that regular low volume training in a pool disinfected by ozone can reduce lung epithelial damage when compared with training in a chlorinated pool. Daily training volumes of $500 \pm 300 \mathrm{~m}$ (50 minutes) two to three times per week for 3 months in a chlorinated pool (free chlorine $1.1 \pm 0.3 \mathrm{mg} / \mathrm{L}$ ) increased basal plasma CC16 by $55 \%$ in healthy adults. However, in those training in an ozone disinfected pool (total bromine $1.8 \pm 0.3$ $\mathrm{mg} / \mathrm{L}), \mathrm{CC} 16$ was unaffected.

Although these studies suggest that airway health may be better protected in the short term when chlorine alternative disinfection methods are used, there is a paucity of longitudinal data. Clearly, more studies are needed to examine if such methods offer long-term protection against the magnitude of airway dysfunction that may develop over time. Similarly, training outdoors, for example, outdoor swimming pools, seas, lakes, or rivers, may reduce the exposure to chlorine by-products. However, climate may make this impractical and other dangers to health may exist.

\section{Conclusion}

There is now compelling evidence that the combined effects of chronic endurance exercise and exposure to chlorine byproducts can lead to airway dysfunction in elite swimmers, even in those with no prior history of respiratory disorders. However, airway dysfunction does not appear to be a barrier to success in elite swimmers nor does it appear to negatively impact lung growth.

The traditional view that the relatively high prevalence of airway dysfunction observed in swimming is reflective of a selection bias can now be refuted. What is unclear is what the critical cumulative chronic endurance exercise and chlorine by-product exposure are. Given the complexity and number of factors that can impact airway remodeling and dysfunction, this will not be a simple question to answer. Based on the lim- ited evidence available, a best estimate is that a minimum of 4 years of competitive swimming consisting of several $(>10)$ training hours per week is required for dysfunction to develop in healthy swimmers. However, this estimation is made cautiously, especially as competitive swimming will naturally be preceded by a period of noncompetitive swimming during which appropriate skill and fitness levels are developed.

Given the independent effect of chronic endurance exercise on airway remodeling, it is unlikely that changing swimming pool disinfection methods will prevent the development of airway dysfunction in elite swimmers. However, findings from studies comparing the impact of chlorine versus nonchlorine water disinfection methods suggest that chlorine alternatives (such as copper/silver and ozone) subject the airways to less stress. If the results of such studies, which have focused on short-term airway responses, translate into long-term benefits, the prevalence of airway dysfunction in elite swimmers could be reduced by adopting chlorine alternative disinfection methods. Longitudinal studies are required to investigate this possibility.

\section{Disclosure}

The author reports no conflicts of interest in this work.

\section{References}

1. International Olympic Committee. IOC Consensus Statement on Asthma in Elite Athletes; January 2008. Available from: www.olympic.org/ Documents/Reports/E/en_report_1301.pdf. Accessed January 3, 2016.

2. Carlsen KH, Andersen SD, Bjrmer L, et al. Exercise-induced asthma, respiratory and allergic disorders in elite athletes: epidemiology, mechanisms and diagnosis: Part I of the report from the Joint Task Force of the European Respiratory Society (ERS) and the European Academy of Allergy and Clinical Immunology (EEACI) in cooperation with GA²LEN. Allergy. 2008;63:387-403.

3. Fitch KD. An overview of asthma and airway hyper-responsiveness in Olympic athletes. Br J Sports Med. 2012;46:413-416.

4. Mountjoy M, Fitch K, Boulet LP, Bougault V, van Mechelen W, Verhagen E. Prevalence and characteristics of asthma in the aquatic disciplines. J Allergy Clin Immunol. 2015;36:588-594.

5. Fitch KD, Morton AR. Specificity of exercise in exercise-induced asthma. BMJ. 1971;4:577-581.

6. Bar-Or O, Inbar O. Swimming and asthma benefits and deleterious effects. Sports Med. 1992;14:397-405.

7. Font-Ribera L, Villanueva CM, Nieuwenhuijsen MJ, Zock JP, Kogevinas M, Henderson J. Swimming pool attendance, asthma, allergies, and lung function in the Avon Longitudinal Study of Parents and Children cohort. Am J Respir Crit Care Med. 2011;183:582-588.

8. Geiger K, Henschke, N. Swimming for children and adolescents with asthma. BMJ. 2015;49:835-836.

9. Silva GAJ, Andriolo BNG, Riera R, Parra SA, Peccin MS. Water-based exercise for adults with asthma (review). Cochrane Database Syst Rev. 2014; 7:CD003316:1-36.

10. Pedersen L, Lund TK, Barnes PJ, Kharitonov SA, Backer V. Airway responsiveness and inflammation in adolescent elite swimmers. JAllergy Clin Immunol. 2008a;122:322-328.

11. Rotman HH, Fliegelman MJ, Moore T, et al. Effects of low concentrations of chlorine on pulmonary function in humans. J Appl Physiol Respir Envrion Exerc Physiol. 1983;54:1120-1124. 
12. Massin N, Bohadana AB, Wild P, Héry M, Toamain JP, Hubert G. Respiratory symptoms and bronchial responsiveness in lifeguards exposed to nitrogen trichloride in indoor swimming pools. Occup Environ Med. 1998;55:258-263.

13. Jacobs JH, Spaan S, van Rooy GBGJ, et al. Exposure to trichloramine and respiratory symptoms in indoor swimming pool workers. Eur Respir J. 2007;29:690-698

14. Belda J, Riscart S, Casan P, et al. Airway inflammation in the elite athlete and type of sport. Br J Sports Med. 2008;42:244-249.

15. Bougault V, Loubaki L, Joubert P, et al. Airway remodelling and inflammation in competitive swimmers training in indoor chlorinated swimming pools. J Allergy Clin Immunol. 2012;129:351-358.

16. Bernard A, Nickmilder M, Dumont X. Chlorinated pool attendance, airway epithelium defects and the risks of allergic diseases in adolescents: interrelationships revealed by circulating biomarkers. Environ Res. 2015;140:119-126.

17. Rosenman KD, Millerick-May M, Reilly MJ, et al. Swimming facilities and work-related asthma. J Asthma. 2015;52:52-58.

18. di Prampero PE. The energy cost of human locomotion on land and in water. Int J Sports Med. 1986;7:55-72.

19. McArdle WD, Glaser RM, Magel, JR. Metabolic and cardiorespiratory response during free swimming and treadmill walking. J Appl Physiol. 1971;30:733-738.

20. Holmér I. Oxygen uptake during swimming in man. J Appl Physiol. 1972;33:502-509.

21. Holmér I, Lundin A, Eriksson BO. Maximum oxygen uptake during swimming and running by elite swimmers. J Appl Physiol. 1974;36:711-714.

22. Holmér I, Stein EM, Saltin SB, Ekblom B, Astrand PO. Hemodynamic and respiratory responses compared in swimming and running. $J \mathrm{Appl}$ Physiol. 1974;37:49-54.

23. Rodriguez FA. Maximal oxygen and cardiorespiratory response to maximal 400-m free swimming, running and cycling tests in competitive swimmers. $J$ Sports Med Phys Fit. 2000;40:87-95.

24. Roels B, Schmitt L, Libicz S, Bentley D, Richalet JP, Millet G. Specificity of $\mathrm{VO}_{2} \max$ and the ventilatory threshold in free swimming and cycle ergometry: comparison between triathletes and swimmers. $\mathrm{BrJ}$ Sports Med. 2005;39:965-968.

25. Lundgren CEG. Immersion effects. In: The Lung at Depth.Lundgren CEG, Miller JN editors. New York: Marcel Dekker Inc.; Chapter 3; 1999: 91-128.

26. Robertson $\mathrm{CH}$, Engle CM, Bradley ME. Lung volumes in man immersed to the neck: dilution and plethysmographic techniques. J Appl Physiol Respir Environ Exerc Physiol. 1978;44:679-682.

27. Jarrett AS. Effect of immersion on intrapulmonary pressure. $J$ Appl Physiol. 1965;20:1261-1266.

28. Burger EJ, Macklem P. Airway closure: demonstration by breathing $100 \% \mathrm{O}_{2}$ at low lung volumes and by $\mathrm{N}_{2}$ washout. $J$ Appl Physiol. 1968;25:139-148.

29. Rowell LR. Human Circulation Regulation During Physical Stress. New York: Oxford University Press; 1986.

30. Agostoni E, Gurtner G, Torri G, Rahn H. Respiratory mechanics during submersion and negative-pressure breathing. J Appl Physiol. 1966;21:251-258.

31. Withers RT, Hamdorf PA. Effect of immersion on lung capacities and volumes: implications for the densitometric estimation of relative body fat. J Sports Sci. 1989;7:21-30.

32. Hong SK, Ting EY, Rahn H. Lung volumes at different depths of submersion. J Appl Physiol. 1960;15:550-553.

33. Craig AB, Dvorak M. Expiratory reserve volume and vital capacity of the lungs during immersion in water. J Appl Physiol. 1975;38:5-9.

34. Cordain L, Stager J. Pulmonary structure and function in swimmers. Sports Med. 1988;6:271-278.

35. Cordain L, Tucker A, Moon D, Stager JM. Lung volumes and maximal respiratory pressures in collegiate swimmers and runners. Res $Q$ Exerc Sport. 1990;61:70-74.

36. Armour J, Donnelly PM, Bye PTP. The large lungs of elite swimmers: an increased alveolar number? Eur Resp J. 1993;6:237-247.
37. Magel JR, Faulkner JA. Maximum oxygen uptakes of college swimmers. J Appl Physiol. 1967;22:929-938.

38. Bernard A. Chlorination products: emerging links with allergic diseases. Curr Med Chem. 2007;14:1771-1782.

39. World Health Organization. Guidelines for Safe Recreational Water Environments Volume 2 Swimming Pools and Similar Environments. France: World Health Organization; 2006.

40. Pool Water Treatment Advisory Group. The Management and Treatment of Swimming Pool Water - Code of Practice; 2013. Available from: www.edlc.co.uk/pdf/PWTAG\%20CodeofPractice1.13v5_000.pdf. Accessed September 25, 2015.

41. Wheatley JR, Amis TC, Engel LA. Oronasal partitioning of ventilation during exercise in humans. J Appl Physiol. 1991;71:546-551.

42. Bonsignore MR, Morici G, Riccobono L, et al. Airway cells after swimming outdoors or in the sea in nonasthmatic athletes. Med Sci Sports Exerc. 2003;35:1146-1152.

43. Martin N, Lindley MR, Hargadon B, Monteiro WR, Pavord ID. Airway dysfunction and inflammation in pool- and non-pool-based elite athletes. Med Sci Sports Exerc. 2012;44:1433-1439.

44. Bougault V, Turmel J, St-Laurent J, Bertrand M, Boulet LP. Asthma, airway inflammation and epithelial damage in swimmers and cold-air athletes. Eur Respir J. 2009;33:740-746.

45. Daviskas E, Gonda I, Anderson SD. Local airway heat and water vapour losses. Respir Physiol. 1991;84:115-132.

46. Kippelen P, Anderson SD. Airway injury during high-level exercise. $\mathrm{Br}$ J Sports Med. 2012;46:385-390.

47. Kippelen P, Fitch KD, Anderson SD, et al. Respiratory health of elite athletes - preventing airway injury: a critical review. Br J Sports Med. 2012;46:471-476.

48. Bussotti M, di Marco S, Marchese G. Respiratory disorders in endurance athletes - how much do they really have to endure? Open Access J Sports Med. 2014;5:47-63.

49. Williams AE. Immunology Mucosal and Body Surface Defences. UK: Wiley-Blackwell; 2012.

50. Moreira A, Palmares C, Lopes C, Delgado L. Airway vascular damage in elite swimmers. Resp Med. 2011;105:1761-1765.

51. Anderson SD, Kippelen P. Exercise-induced bronchoconstriction: pathogenesis. Curr Allergy Asthma Rep. 2005;5:116-122.

52. Cockcroft DW, Davis BE. Mechanisms of airway hyperresponsiveness. J Allergy Clin Immunol. 2006;118:551-559.

53. Persson CGA, Erjefält JS, Andersson M, Greiff L, Svensson C. Extravasation, lamina propria flooding and luminal entry of bulk plasma exudate in mucosal defence, inflammation and repair. Pulm Pharmacol. 1996;9:129-139.

54. Helenius IJ, Rytilä P, Metso T, Haahtela T, Venge P, Tikkanen HO. Respiratory symptoms, bronchial responsiveness, and cellular characteristics of induced sputum in elite swimmers. Allergy. 1998;53:346-352.

55. Lagerkvist BJ, Bernard A, Blomberg A, et al. Pulmonary epithelial integrity in children: relationship to ambient ozone exposure and swimming pool attendance. Environ Health Perspect. 2004;112: 1768-1771.

56. Bernard A, Carbonnell S, Michel $\mathrm{O}$, et al. Lung hyperpermeability and asthma prevalence in schoolchildren: unexpected associations with the attendance at indoor chlorinated swimming pools. Occup Environ Med. $2003 ; 60: 385-394$

57. Romberg K, Bjermer L, Tufvesson E. Exercise but not mannitol provocation increases urinary Clara cell protein (CC16) in elite swimmers. Respir Med. 2011;105:31-36.

58. Pedersen L, Lund TK, MØlgaard E, Kharitonov SA, Barnes PJ, Backer $\mathrm{V}$. The acute effect of swimming on airway inflammation in adolescent elite swimmers. J Allergy Clin Immunol. 2009;123:502-504.

59. Silvestri M, Crimi E, Oliva S, et al. Pulmonary function and airway responsiveness in young competitive swimmers. Pediatr Pulmonol. 2013;48(1):74-80.

60. Carraro S, Pasquale MF, da Frè M, et al. Swimming pool attendance and exhaled nitric oxide in children. J Allergy Clin Immunol. 2006;118: 958-960. 
61. Pedersen L, Winter S, Backer V, Anderson SD, Larsen KR. Airway responses to eucapnic hyperpnea, exercise, and methacholine in elite swimmers. Med Sci Sports Exerc. 2008;40:1567-1572.

62. Stadelmann K, Stensrud T, Carlsen KH. Respiratory symptoms and bronchial responsiveness in competitive swimmers. Med Sci Sport Exerc. 2011;43:375-381.

63. Zwick H, Popp W, Budik G, Wanke T,Rauscher, H. Increased sensitization to aeroallergens in competitive swimmers. Lung. 1990;168:111-115.

64. Helenius IJ, Tikkanen, HO, Sarna S, Haahtela T. Asthma and increased bronchial responsiveness in elite athletes: atopy and sport event as risk factors. J Allergy Clin Immunol. 1998;101:646-652.

65. Bougault V, Turmel J, Boulet LP. Airway hyperresponsiveness in elite swimmers: Is it a transient phenomenon. J Allergy Clin Immunol. 2011;127:892-898.

66. Dickinson JW, Whyte GP, McConnell AK, Harries MG. Impact of changes in the IOC-MC asthma criteria: a British perspective. Thorax. 2005;60:629-632.

67. Arie S. London 2012 Olympics - what can we learn from asthma in elite athletes. BMJ. 2012;344(e2556):1-3.

68. World Anti-Doping Agency. TUE Physician Guidelines Medical Information to Support the Decisions of TUE Committees Asthma. Available from: http://www.wada-ama.org/en/resources/therapeutic-use-exemption-tue/medical-information-to-support-the-decisions-of-tuecsasthma. Accessed January 10, 2016.

69. Helenius IJ, Rytilä P, Sarna S, et al. Effect of continuing or finishing high-level sports on airway inflammation, bronchial hyperresponsiveness, and asthma: A 5-year prospective follow-up study of 42 highly trained swimmers. J Allergy Clin Immunol. 2002;109. 962-968.

70. Clearie KL, Vaidyanathan S, Williamson PA, et al. Effects of chlorine and exercise on the unified airway in adolescent elite Scottish swimmers. Allergy. 2009;65:269-273.

71. Carbonnelle S, Francaux M, Doyle I, et al. Changes in serum pneumoproteins caused by short-term exposure to nitrogen trichloride in indoor chlorinated swimming pools. Biomarkers. 2002;7: 464-478.

72. Carbonnelle S, Bernard A, Doyle IR, Grutters J, Francaux M. Fractional exhaled NO and serum pneumoproteins after swimming in a chlorinated pool. Med Sci Sports Exerc. 2008;40:1472-1476.
73. Fernández-Luna Á, Gallardo LM, Plaza-Carmona MP, et al. Respiratory function and changes in lung epithelium biomarkers after a shorttraining intervention in chlorinated vs. ozone indoor pools. PLoS One. 2013;8(e68447):1-6.

74. Bonen A, Wilson BA, Yarkony M, Belcastro AN. Maximal oxygen uptake during free, tethered, and flume swimming. J Appl Physiol: Respir Environ Exerc Physiol. 1980;48:232-235.

75. Costill DL, Kovaleski J, Porter D, Kirwan J, Fielding R, King D. Energy expenditure during front crawl swimming: predicting success in middledistance events. Int J Sports Med. 1985;6:266-270.

76. Wakayoshi K, Acquisto LTD, Cappaert JM, Troup JP. Relationship between oxygen uptake, stroke rate and swimming velocity in competitive swimming. Int J Sports Med. 1995;16:19-23.

77. Ogital F, Hara M, Tabata I. Anaerobic capacity and maximal oxygen uptake during arm stroke, leg kicking and whole body swimming. Acta Physiol Scand. 1996;157:435-441.

78. Fernanades RJ, Billat VL, Cruz AC, Colaco PJ, Cardoso CS, Vilas-Boas JP. Does net energy cost of swimming affect time to exhaustion at the individual's maximal oxygen consumption velocity? J Sports Med Phys Fitness. 2006;46:373-380.

79. Reis JF, Alves FB, Bruno PM, Vleck V, Millet GP. Effects of aerobic fitness on oxygen uptake kinetics in heavy intensity swimming. Eur $J$ Appl Physiol. 2012;112:1689-1697.

80. McClaran SR, Wetter TJ, Pegelow DF, Dempsey JA. Role of expiratory flow limitation in determining lung volumes and ventilation during exercise. J Appl Physiol. 1999;86:1357-1366.

81. Adir Y, Shupak A, Gil A, et al. Swimming-induced pulmonary edema clinical presentation and serial lung function. Chest. 2004;126:394-399.

82. Helenius I, Lumme A, Haahtela T. Asthma, airway inflammation and treatment in elite athletes. Sports Med. 2005;35:565-574.

83. Guenette JA, Sheel AW. Physiological consequences of a high work of breathing during heavy exercise in humans. J Sci Med Sports. 2007; 10:341-350

84. Gelardi M, Ventura MT, Fiorella R, et al. Allergic and non-allergic rhinitis in swimmers: clinical and cytological aspects. Br J Sports Med. 2012;46:54-58.

85. Molis MA, Molis, WE. Exercise-induced bronchospasm. Sports Health. 2010;2:311-317.

86. West JB. Pulmonary Pathophysiology the Essentials. 8th ed. Philadelphia, PA: Lippincott Williams \& Wilkins; 2013.
Open Access Journal of Sports Medicine

\section{Publish your work in this journal}

The Open Access Journal of Sports Medicine is an international, peer-reviewed, open access journal publishing original research, reports, reviews and commentaries on all areas of sports medicine. The journal is included on PubMed. The manuscript management system is completely online and includes a very quick and fair

\section{Dovepress}

peer-review system. Visit http://www.dovepress.com/testimonials.php to read real quotes from published authors. 